\title{
Investigating and modelling risk factors for primary postpartum haemorrhage among childbearing Women in the Northern Province of Rwanda: A Case Control Study
}

Oliva Bazirete ( $\square$ baziretoliva@gmail.com )

University of Rwanda

Manassé Nzayirambaho

University of Rwanda

Aline Umubyeyi

University of Rwanda

Innocent Karangwa

University of the Western Cape

Marilyn Evans

Western University

\section{Research Article}

Keywords: Postpartum haemorrhage, Case-control study, risk ratio, Risk factors, Prevention, Rwanda.

Posted Date: February 23rd, 2021

DOI: https://doi.org/10.21203/rs.3.rs-222735/v1

License: (c) (i) This work is licensed under a Creative Commons Attribution 4.0 International License.

Read Full License 


\title{
Investigating and modelling risk factors for primary postpartum haemorrhage among childbearing Women in the Northern Province of Rwanda: A Case Control Study
}

\author{
Authors: Oliva Bazirete ${ }^{1 *}$; Manassé Nzayirambaho ${ }^{1}$, Aline Umubyeyi ${ }^{1}$, Innocent Karangwa ${ }^{2}$, Marilyn \\ Evans $^{3}$
}

\author{
Affiliation and Correspondence \\ ${ }^{1}$ University of Rwanda, College of Medicine and Health Sciences, Rwanda \\ ${ }^{2}$ University of the Western Cape, Republic of South Africa \\ ${ }^{3}$ Western University, Canada \\ *Email: baziretoliva@gmail.com
}

\section{Affiliation}

1. Oliva Bazirete, Email address: baziretoliva@gmail.com; University of Rwanda, Rwanda.

2. Prof. Manassé Nzayirambaho, Email address: mnzayira@nursph.org, University of Rwanda, Rwanda.

3. Dr Innocent Karangwa, Email address: ikarangwa@uwc.ac.za, University of the Western Cape, South Africa

4. Ass. Prof. Aline Umubyeyi, Email address: aumubyey@ nursph.org, University of Rwanda, Rwanda.

5. Prof. Marilyn Evans, Email address: mevans26@uwo.ca, Western University, Canada

\section{Corresponding author*}

Ms Oliva Bazirete, 


\section{Abstract}

Background: The vast majority of maternal deaths occur in Low- and Middle-Income Countries. Postpartum haemorrhage (PPH) remains a major global burden contributing to high maternal mortality and morbidity rates. Assessment of PPH risk factors should be undertaken during antenatal, intrapartum and postpartum periods for timely prevention of maternal morbidity and mortality associated with PPH. The aim of this study is to investigate and model risk factors for primary PPH in Rwanda.

Methods: We conducted an observational case-control study of 430 (108 cases: 322 controls) pregnant women with gestational age of 32 weeks and above who gave birth in five selected health facilities of Rwanda between January and June 2020. Poisson regression, a generalized linear model with a log link and a Poisson distribution was used to estimate the risk ratio of factors associated with PPH. The research protocol was approved by the University of Rwanda, College of Medicine and Health Sciences Institutional Ethics Review Board.

Results: The overall prevalence of primary PPH was $25.2 \%$. The following risk factors were identified: antepartum haemorrhage ( $\mathrm{RR}=3.36$; $95 \% \mathrm{CI} 1.80-6.26, P<0.001)$; intrauterine fetal death (RR=1.93; 95\% CI 0.93- 4.03, $P<0.077)$; multiple pregnancy (RR=1.83; 95\% CI 1.11- 3.01, $P=0.016)$; haemoglobin level $<11 \mathrm{gr} / \mathrm{dL}(\mathrm{RR}=1.51 ; 95 \% \mathrm{CI} 1.00-2.30, P=0.050)$, and premature rupture of membranes $(\mathrm{RR}=0.58 ; 95 \%$ CI $0.32-1.05, P<0.077)$. During the intrapartum and immediate postpartum period, the main causes of primary PPH were: uterine atony ( $R R=6.70$; 95\% CI 4.78- 9.38, $P<0.001)$, retained tissues (RR=4.32; 95\% CI 2.87- 6.51, $P<0.001)$; and lacerations of genital organs after birth $(\mathrm{RR}=2.14$; $95 \%$ CI 1.49- 3.09, $P<0.001)$. Coagulopathy was not prevalent in primary $\mathrm{PPH}$.

Conclusion: Based on our findings, uterine atony remain the foremost cause of primary PPH. As well as other established risk factors for PPH, antepartum haemorrhage and intra uterine fetal death should be included as risk factors in the development and validation of prediction models for PPH. Large scale studies are needed to investigate further potential PPH risk factors.

Keywords: Postpartum haemorrhage, Case-control study, risk ratio, Risk factors, Prevention, Rwanda. 


\section{Background}

Maternal mortality remains unacceptably high worldwide [1]. According to the World Health Organization (WHO), approximately 295000 women died during pregnancy or after childbirth in 2017. The vast majority of these deaths (94\%) occurred in low-resource settings, and most could have been prevented [1]. The maternal mortality ratio (MMR) in Rwanda is reported to be 203/100,000 live births [2]. Reduction of maternal mortality has long been a global health priority, and a target in the United Nations (UN) 2030 agenda for Sustainable Development Goals is to reduce the global MMR to less than 70 per 100,000 live births [3].

Most maternal complications develop during pregnancy and many are preventable or treatable. Complications, such as maternal obesity, curettage in previous pregnancy, hypertensive diseases, haemoglobin $(\mathrm{Hb})$ level less than or equal to $10 \mathrm{~g} / \mathrm{dL}$ [4] may exist before pregnancy and may pose problems during pregnancy leading to PPH, especially if not managed as part of the woman's care [1]. Primary postpartum haemorrhage (PPH), clinically defined as a blood loss of $500 \mathrm{ml}$ or more following a normal vaginal delivery (NVD) or $1000 \mathrm{ml}$ or more following a caesarean section within 24 hours after birth [5, 6], is a major cause of maternal mortality and severe morbidity, particularly in developing countries [7]. WHO [5] indicates that most maternal deaths resulting from PPH occur within the first 24 hours postpartum and are preventable and manageable if appropriate and effective resources are readily available. In a nationwide facility-based retrospective cohort study of a maternal death audit conducted in Rwanda [8]; $70 \%$ of reported maternal deaths were due to direct causes, of which PPH was the leading one $(22.7 \%$ of all reported cases). These figures demonstrate that the rate of dying due to PPH in Rwanda, remains high compared to average rates of dying due to PPH in developed countries (8\%). WHO works to contribute to the reduction of maternal mortality by increasing research evidence, providing evidence-based clinical and programmatic guidance [1]. Consequently, PPH has received increasing attention as a quality indicator for obstetric care [9]. Recent studies have shown an increasing trend in $\mathrm{PPH}$, but the causes for this increase are still uncertain [10].

PPH is the consequence of several different factors that can occur in isolation or combination, such as: uterine atony, retained placental tissue, genital tract trauma and coagulation dysfunction (the '4Ts' mnemonic: tone, tissue, trauma, and thrombin) $[5,11]$. Most cases of PPH are caused by 
uterine atony $[11,12]$ where the loss of myometrial tone allows maternal blood flow to the placental bed and the bleeding continues unchecked. Conversely, studies conducted in Nigeria and Ethiopia [13-15] demonstrated that the commonest causes of PPH were genital trauma and retained placenta.

Primary PPH may develop in women with no risk factors [16] and only about one-third of PPH cases have identifiable risk factors [7]. A growing body of literature has investigated predictors of PPH in different countries. These predictors include: previous PPH [9, 17-19], mother's age 35 years or above [18-21], hypertensive disorders in pregnancy [6, 9, 21, 22], prolonged labour or complication during labour [6, 19, 23, 24], operative vaginal delivery and instrumental vaginal deliveries $[19,25,26]$, multiparity $[20,23,24]$, multiple pregnancy $[9,18]$, Hb less than 10gr/dL on admission to labour, ante-partum anaemia [22, 25-27], fundal height of $38 \mathrm{~cm}$ or above or large baby [18, 22, 25], placenta praevia [28, 29] and induction of labour [24, 30].

A number of studies have also attempted to examine other predictors of PPH: delivery by Caesarean section[18, 30], gestational age of 40 weeks of amenorrhoea and above [7, 22], curettage in prior pregnancy, nulliparous or receiving pethidine in labour [22], gestational diabetes mellitus, body mass index (BMI) of 25 or above before pregnancy [21] and chorioamnionitis [31]. HIV positive status was found to be associated with $\mathrm{PPH}$ in a prospective cohort study conducted by Ononge et al., [18] in Uganda.

Severe morbidities associated with PPH include anaemia and need for blood transfusion, disseminated intravascular coagulation, hysterectomy, and renal or liver failure [32]. Women who develop PPH may also suffer from complications including: hepatic failure, acute respiratory distress syndrome, need for open surgery, need for intensive care, disseminated intravascular coagulation, hysterectomy and cardiac arrest $[33,34]$. In moderate complications, PPH can lead to minor anaemia, fatigue, depression and separation anxiety [33, 35].

Interest in PPH has predominantly focused on the evaluation of its risk factors, prevention, and treatment [32]. Other studies have attempted to understand the reasons for substandard care in PPH [32, 36], accurate diagnosis [37-39] and identification of potentially severe cases [19]. To 
date, little is known about risk factors of primary PPH investigated through a case control study in a Rwandan setting. Therefore, the purpose of this study is to investigate and model the risk factors of primary PPH among women admitted in postpartum units of selected health facilities. The key contribution of this work is the solution it provides for a proactive prevention of primary PPH.

\section{Methods}

\section{Study design}

The present study is part of a larger exploratory sequential mixed-methods study. This is the third phase of the larger study: an observational case control study $[40,41]$ to investigate and model the risk factors for PPH. This study was preceded by a scoping review [4] which described the research output on factors affecting the prevention of PPH in low and middle income countries and a qualitative descriptive study [42] to explore influencing factors for prevention of PPH and early detection of women at risk in Northern Province of Rwanda as perceived by beneficiaries and health workers. These two studies led to developing a content validated risk assessment tool for the prediction and prevention of PPH (RATP) [43]. The findings from one phase of the larger exploratory sequential mixed-methods study informed the subsequent phases. Therefore, this case control study used the PPH risk assessment tool (RATP) developed during the preceding phase.

\section{Population and setting}

The target population was women aged 18 years or above, admitted to the postpartum ward after a live birth at $\geq 32$ weeks' gestation at the health facilities of the Northern Province of Rwanda during the period January $1^{\text {st }} 2020$ to June $30^{\text {th }} 2020$. We sent invitations to participate to six health facilities: 5 hospitals and one medicalised health centre. Four district hospitals and one medicalised health centre provided permission to conduct the study. Therefore, five health facilities were included in this study while one district hospital was excluded. A medicalised health centre is a new level in the health system of Rwanda deployed with capable staff (medical doctor, nurses and midwives, paramedics, anaesthesia, etc...). It is the level in between district hospital and health centre, which is equipped to attend to patients with acute life threatening conditions especially obstetric conditions [44]. The selection criteria of health facilities included their level of

performance in maternal and newborn health (a significant number of births per month compared to others health facilities in the same locality), location (rural versus urban), and the geographical accessibility of the health facilities to clients. Considering that the northern province is 
characterised by a hilly terrain, some inhabitants have difficulties to reach the health facilities as indicated by participants in a recent study[42]. The study sites were selected by the principal investigator and validated by the research committee. The Northern Province of Rwanda was purposively chosen for being in a rural area where some health centres are hard to access, and for its low uptake of antenatal and postnatal services among childbearing women [45].

\section{Participants and data collection procedures}

From the target population, the source population for the present case control study was selected to identify the outcome of interest as suggested by Song and Chung [41]. Hence, women in the postpartum period were our source population. A PPH case in our study is defined as blood loss of $500 \mathrm{ml}$ or above within the first hour which is visually estimated by health care providers observing women who change the blood-soaked vaginal pads 2 times or more within the first hour after birth [5, 46, 47]. Primary PPH is also counted in case woman requires a blood transfusion for excessive bleeding after birth due to clinical symptoms and signs of anaemia or hemodynamic decompensation after birth [9] or with $\mathrm{Hb}$ level less than $11 \mathrm{gr} / \mathrm{dL}$ especially if symptomatic according the findings from Rwanda Demographic Health Survey 2019-20 [2]. Women who received a blood transfusion because of postpartum anaemia, without evidence of excessive blood loss after birth were excluded from this study. Women with secondary PPH which is characterised by vaginal blood loss (or lochia discharges) at least 24 hours after birth or six weeks after delivery[48], were also excluded from this study. The attending health care provider estimated the blood loss visually in all five health facilities. Controls were a random sample of all deliveries without primary PPH from the same source population and period of time as the cases of primary PPH. Based on the list in the birth registry, after identifying the case of PPH, the three following women who gave birth without primary PPH were selected as control cases. Hence inclusion criteria were being aged of 18 years and above, being admitted for postpartum monitoring at the health facility within the first 24 hours after birth.

After selecting eligible women for inclusion in the present study, we extracted the study participants [41], that included all cases confirmed to have primary PPH $(n=108)$ and a random sample of controls without primary PPH (n =322) (Fig 1) to make a total sample size of 430 participants. Due to a limited study period, the number of study participants was slightly lower than the target sample size. A G*Power software for power analysis [49] indicated that we needed 
118 cases and 354 controls considering three controls per case, with type I error of 5\%, power of $80 \%$, frequency of risk factors in control subjects of $0.2 \%$, and cases with potential risk factors to PPH being almost twice as likely to be exposed to PPH compared to controls (odds ratio $(\mathrm{OR})=$ $1.8)$.

\section{SOURCE POPULATION}

All women giving birth in the 5 selected health facilities of the Northern Province of Rwanda

January, $1^{\text {st }} 2020$ - June $30^{\text {th }} 2020$

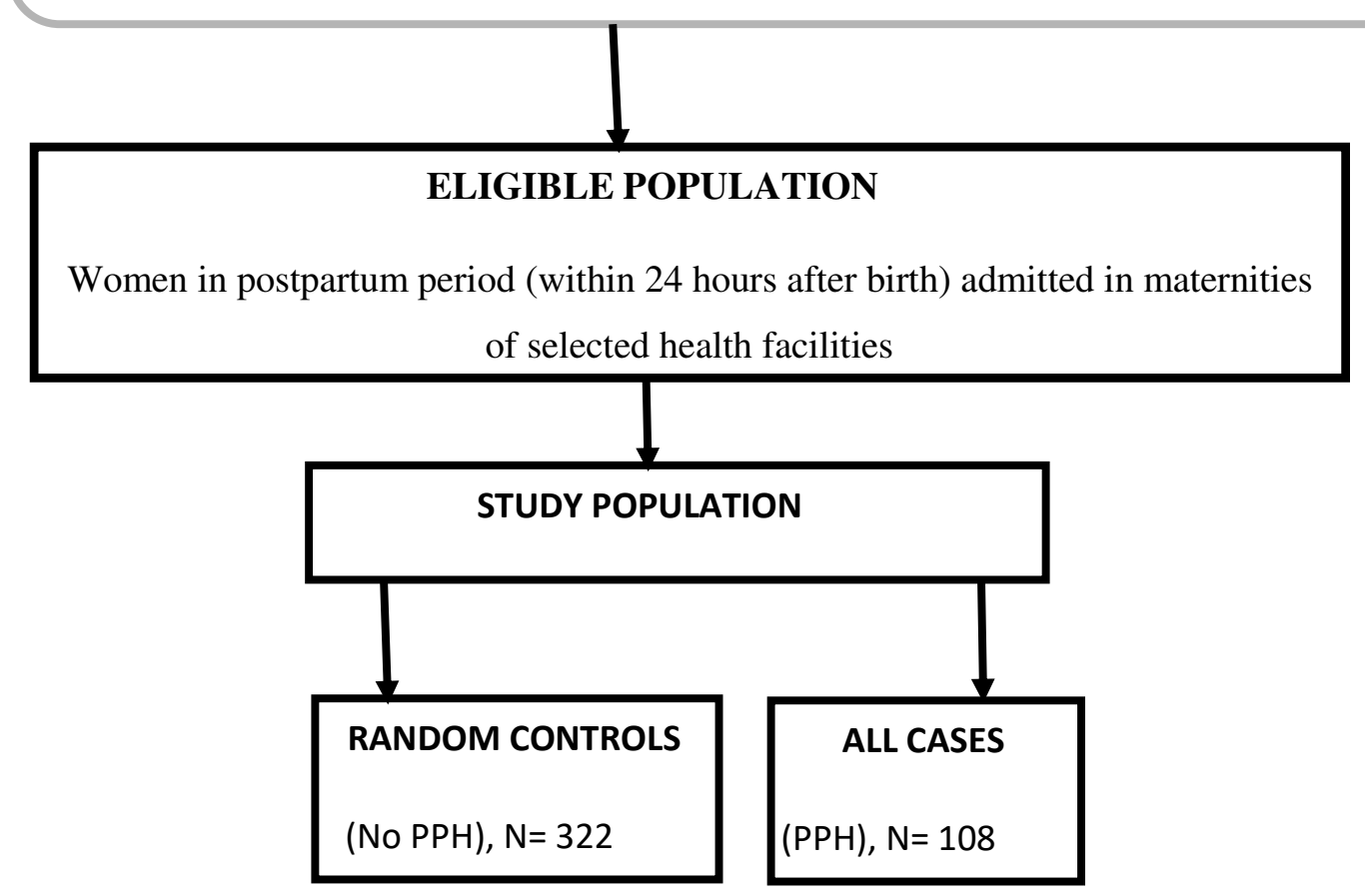

Figure 1: Selection of study subjects. PPH: Postpartum haemorrhage

One research assistant at each of the five health facilities was recruited by the principal investigator and selected in agreement with the health facilities' administration. The research assistants were all registered midwives with experience in PPH prevention and had two or more years of experience working full time in maternity. Prior to the period of data collection, the principal investigator organised a one-day training for the research assistants to have a common understanding on research aim, ethical principles, data collection tool and methods for data collection using the RATP [43]. To start data collection, research assistants verbally invited women in postpartum period who met inclusion criteria to take part in the study, told them about the study. Those who agreed to participate signed to indicate informed consent. Data was collected 
during the hospital stay of the woman to allow the research assistant to visit the client and cross check data. Accessing clients' charts facilitated the assessment of eligibility of study participants. Therefore, registration of client data was based on information collected from clients' files, from maternity records completed on a regular basis on women in labour and birth, also documenting the birth outcomes, including cases that experienced blood loss during birth and immediately after birth. We also collected client data through structured interviews carried out by the research assistant with the women using the RATP to ensure the accuracy of data and to minimise missing data. After identifying a case of PPH, the research assistant was required to also identify three control participants who gave birth and who did not experience PPH within +/- 24 hours in relation to the time the PPH happened.

The RATP was translated from English to French and Kinyarwanda by a professional translator to facilitate respondents' understanding of the tool by using their preferred language. The three languages are officially used in Rwanda. Back translation was done by an independent professional translator, to confirm that the meaning and content of the questions of the original copy had not been changed during the translation. Verification of the translated instrument was also done to ensure its validity.

As the research assistants were full-time staff working in maternity, they were able to identify cases who experienced PPH after birth during their working days. For some cases of PPH that happened during their days off, the research assistants could identify potential participants through maternity records (daily reports) and confirm whether the woman had primary PPH by asking the woman if she bled heavily and changed the blood-soaked vaginal pads two or more times during the first 24 hours after birth. The principal investigator made regular visits to the research sites during the data collection period to ensure that data collection was being conducted as planned.

\section{Variables under study}

The dependent variable in this study was primary PPH (presence or absence of primary PPH: Case and Controls) while the presence or absence of the potential PPH risk factors among PPH and control cases were the independent variables. The RATP consists of three sections. The first, Section A consist of social and demographic characteristics of the woman: age, marital status, level of education, area of residence, accessibility to nearest health facility, use of medical insurance, use of family planning methods outside pregnancy, health facility where delivery took place, socio 
economic status and religion. Section B included newborn and mother anthropometry and $\mathrm{Hb}$ measurements: newborn weight, woman weight, woman height and woman $\mathrm{Hb}$ level. Section $\mathrm{C}$ focused on pregnancy, obstetric, intrapartum and immediate postpartum factors: primiparity, Grandmultiparity, uterine anomaly, uterine surgery (e.g. myomectomy), previous caesarean section, previous PPH, antepartum haemorrhage, HIV positive status, multiple pregnancy, anaemia, gestational diabetes mellitus, polyhydramnios, anticoagulant medications in pregnancy, severe pre-eclampsia, intra-uterine foetal death, premature rupture of membranes, prolonged labour, spontaneous vaginal delivery, instrumental vaginal delivery, in labour caesarean section, repeat caesarean delivery, labour induction, labour augmentation, administration of oxytocin for active management of the third stage of labour, episiotomy, perineal tear, vaginal wall tear, cervical tear, uterine rupture, retained tissues, uterine atony with full bladder and uterine atony with uterine inversion.

\section{Data Analysis:}

All 430 completed risk assessment tools (108 cases and 322 controls) were captured in an Excel spreadsheet which was exported to STATA version 15.1 to perform data analysis[50]. Data were cleaned to ensure that there were neither errors nor missing data. For data analysis, we distinguished between causes of and risk factors for PPH. Causes of PPH were classified as the '4Ts' mnemonic [11]: Tone (uterine atony, uterine inversion, placenta abruption and full bladder after birth causing PPH), Tissue (retained placenta and retained parts of placenta, and abnormal placentation), Trauma (uterine rupture, perineal tears and episiotomy, vaginal wall tears, cervical tears), and Thrombin (coagulation disorders, consumption of anti-coagulant medications).

Among the PPH risk factors, maternal age, BMI, birth weight and maternal $\mathrm{Hb}$ were recorded as continuous variables for descriptive purposes and for inclusion in the final model for analysis. Maternal age was divided into 4 groups, below 25 (reference group); 25-29; 30-34; 35 and above [51]. BMI was divided into 4 groups as per WHO's recommendation: <18.5; 18.5-24.9 (reference group); 25-29.9; $\geq 30 \mathrm{~kg} / \mathrm{m} 2$ [52]. Infant birth weight was grouped into three categories: <2500g; 2500-4000g (reference group); $\geq 4000 \mathrm{~g}$ [53]. Hb level of the client at the time of admission to labour was dichotomized as either anaemic $(\mathrm{Hb}<11 \mathrm{gr} / \mathrm{dL})$ or non-anaemic $(\mathrm{Hb} \geq 11 \mathrm{gr} / \mathrm{dL})[2]$. 
Data were analyzed using univariate, bivariate and multivariate techniques [54]. Univariate analysis was used first to summarize data in terms of frequency distributions of the variables under study then bivariate was used to examine the relationship between primary PPH (binary outcome variable) and each risk factor/ cause. The relationship was established between outcome variable (developing or not developing primary PPH among childbearing women in selected health facilities) and independent variables (socio-demographic variables and other potential PPH risk factors under study).

Multivariate analysis was conducted to determine to what extent the significant independent variables are in correlation with the outcome variable. The modified Poisson regression model with robust error variances [55] was used to estimate risk ratios (RRs) and 95\% confidence intervals (CIs). This model was chosen because the outcome of interest (primary PPH) was common [56, 57]. The absence of PPH was used as the reference category because we hypothesized based on previous research $[4,42]$ that the likelihood of PPH would be high with the presence of PPH risk factors relative to none.

Extensive discussion in the literature has reached a consensus that RR is preferred over the odds ratio for most prospective investigations for its scientific meaning [56, 58]. Moreover, odds ratios are considered as more extreme than relative risks when the outcome is not rare [59, 60] (prevalence above $10 \%$ in the study population $[57,61]$ ), and conversion of odds ratios into relative risks is known to produce biased estimates when adjusting for covariates [55, 58].Therefore, Poisson regression, a generalized linear model with a log link and a Poisson distribution was used in this study to estimate the risk ratio because the prevalence of the outcome is not rare (prevalence of primary $\mathrm{PPH}=25 \%$ ) and the outcome variable itself is binary. When the outcome is binary, the exponentiated coefficients are risk ratios instead of incidence-rate ratios[55, 62, 63].The results are reported in the results section.

\section{Results}

Univariate analysis demonstrated that the mean maternal age was higher among PPH cases: 32 years (95\% CI: 30.9-33.9) vs. 29 years (95\% CI: 29.03-30.5) for the control group. 
Table 1 shows that it takes more than one-hour walking time for more than half of participants $(52.1 \%)$ to reach the nearest health facility and less than one-hour for the rest of participants (47.9\%). A majority of participants completed only primary education (80.2\%), $14.4 \%$ attended secondary education while $5.3 \%$ never went to school. Most of the participants $(76.2 \%)$ gave birth at a hospital while $23.8 \%$ were from the medicalized health centre. A large proportion of participants (93.7\%) had a medical insurance. A big number of participants $(76.7 \%)$ were giving birth to a second or subsequent child and 23.2\% were primiparous. Most (88.5\%) received intramuscular oxytocin after birth to manage the third stage of labour.

Table 1: Characteristics of childbearing women included in this study

\begin{tabular}{lcc}
\hline & Frequency & \\
\hline Variable & N & Percent \\
\hline Cases & 108 & 25.1 \\
Controls & 322 & 74.9 \\
Age category & & \\
$<25$ & 100 & 24.1 \\
$25-29$ & 96 & 23.1 \\
$30-34$ & 91 & 21.9 \\
$\geq 35$ & 128 & 30.8 \\
Accessibility to nearest health facility & & \\
Walking time <1hour & 205 & 47.9 \\
Walking time $>$ 1hour & 223 & 52.1 \\
Level of education & & \\
Never went to school & 23 & 5.3 \\
Primary school & 345 & 80.2 \\
Secondary school and above & 62 & 14.4 \\
Place of delivery & & \\
Health Centre & 102 & 23.8 \\
District Hospital & 327 & 76.2 \\
Medical insurance & & \\
No & 27 & 6.3 \\
Yes & 402 & 93.7 \\
Grandmultiparity & & \\
No & 100 & 23.2 \\
Yes & 330 & 76.7 \\
No & 49 & 11.4 \\
Yes & 380 & 88.6 \\
Total & 428 & 100 \\
\hline & & \\
\hline & & \\
\hline & & \\
\hline
\end{tabular}


Results from bivariate analysis of selected demographic and clinical characteristics of women from the two groups are shown in Table 2. As indicated, maternal age, possessing medical insurance, health facility where delivery took place, previous $\mathrm{PPH}$, antepartum haemorrhage (APH), multiple pregnancy, anaemia in pregnancy, level of $\mathrm{Hb}$ on admission to labour, intrauterine foetal death, and BMI were the antepartum risk factors associated with PPH $(P$-value $<0.05)$. Four risk factors were weakly significant: grandmultiparity ( $P$-value of 0.016$)$, premature rupture of membranes (PROM $P$ - value 0.081) and Active Management of Third Stage of Labour (AMSTL) using Oxytocin(p-value 0.094). Differences in the following factors among the two groups (with PPH and without PPH) did not reach statistical significance with a $P$-value greater than 0.05 : caesarean birth and spontaneous vaginal birth, positive HIV status, labour induction and labour augmentation, management of the third stage of labour, pre-eclampsia, polyhydramnios and previous uterine surgery. Hence these factors were not correlated with primary PPH and are not shown in Table 2.

At this level of analysis, the causes of PPH that were found to be associated with primary PPH with a $P$-value of $<0.001$ were uterine atony, and retained tissues. Coagulopathy and lacerations of genital organs were also significantly correlated with PPH but their $P$-value of respectively 0.084 and 0.077 did not meet the 0.05 cut-off set for statistical significance. 
Table 2: The number (n), prevalence (\%); 95\% (CI) and $P$-value of childbearing women with primary postpartum haemorrhage by demographic and clinical characteristics.

\begin{tabular}{|c|c|c|c|c|c|}
\hline \multirow[t]{2}{*}{ Variables } & \multicolumn{2}{|c|}{ Cases(PPH=Yes) } & \multicolumn{2}{|c|}{$(\mathrm{PPH}=\mathrm{No})$} & \multirow[t]{2}{*}{ P-Value } \\
\hline & $\mathbf{n}$ & $\%$ & $\mathbf{n}$ & $\%$ & \\
\hline \multicolumn{6}{|l|}{ Age category } \\
\hline$<25$ (Reference) & 19 & 19 & 81 & 81 & \\
\hline $25-29$ & 21 & 21.8 & 75 & 78.1 & $0.008 * *$ \\
\hline $30-34$ & 18 & 19.7 & 73 & 80.2 & \\
\hline$\geq 35$ & 46 & 35.9 & 82 & 64 & \\
\hline \multicolumn{6}{|l|}{ Health facility where delivery took place } \\
\hline District Hospital & 62 & 18.9 & 265 & 81 & $<0.001^{* * *}$ \\
\hline Health Center (Reference) & 46 & 44.6 & 57 & 55.3 & \\
\hline \multicolumn{6}{|l|}{ Hemoglobin on admission } \\
\hline$<11 \mathrm{gr} / \mathrm{dl}$ (Anaemic) (Reference) & 34 & 54.8 & 28 & 45.1 & $<0.001^{* * *}$ \\
\hline$\geq 11 \mathrm{gr} / \mathrm{dl}$ (Non anaemic) & 73 & 20.2 & 288 & 79.7 & \\
\hline \multicolumn{6}{|l|}{ Body Mass Index } \\
\hline$<18.5$ (Reference) & 4 & 80 & 1 & 20 & \\
\hline $18.5-24.9$ & 76 & 24.6 & 119 & 72.3 & \\
\hline $25-29.9$ & 23 & 17.4 & 109 & 82.5 & $0.004 * *$ \\
\hline$\geq 30$ & 5 & 27.7 & 13 & 72.2 & \\
\hline \multicolumn{6}{|l|}{ Intrauterine foeto-dealth } \\
\hline Yes & 11 & 68.7 & 5 & 31.2 & $<0.001^{* * *}$ \\
\hline No (Reference) & 97 & 23.5 & 315 & 76.4 & \\
\hline \multicolumn{6}{|l|}{ Medical insurance } \\
\hline Yes & 90 & 22.39 & 312 & 77.6 & $<0.001^{* * *}$ \\
\hline No (Reference) & 18 & 64.26 & 10 & 35.7 & \\
\hline \multicolumn{6}{|l|}{ Grandmultiparity } \\
\hline Yes & 92 & 27.8 & 238 & 72.1 & $0.016 * *$ \\
\hline No(Reference) & 16 & 16 & 84 & 84 & \\
\hline \multicolumn{6}{|l|}{ Previous PPH } \\
\hline Yes & 9 & 99 & 6 & 40 & $0.002 * *$ \\
\hline No(Reference) & 60 & 23.8 & 316 & 76.1 & \\
\hline \multicolumn{6}{|l|}{ APH } \\
\hline Yes & 10 & 66.6 & 5 & 33.3 & $<0.001^{* * *}$ \\
\hline No(Reference) & 98 & 23.7 & 315 & 76.2 & \\
\hline \multicolumn{6}{|l|}{ Multiple pregnancy } \\
\hline Yes & 15 & 68.1 & 7 & 31.8 & $<0.001^{* * *}$ \\
\hline No(Reference) & 93 & 22.7 & 315 & 77.2 & \\
\hline \multicolumn{6}{|l|}{ Anemia in pregnancy } \\
\hline Yes & 11 & 84.6 & 2 & 15.3 & $<0.001 * * *$ \\
\hline No(Reference) & 95 & 22.8 & 320 & 77.1 & \\
\hline
\end{tabular}




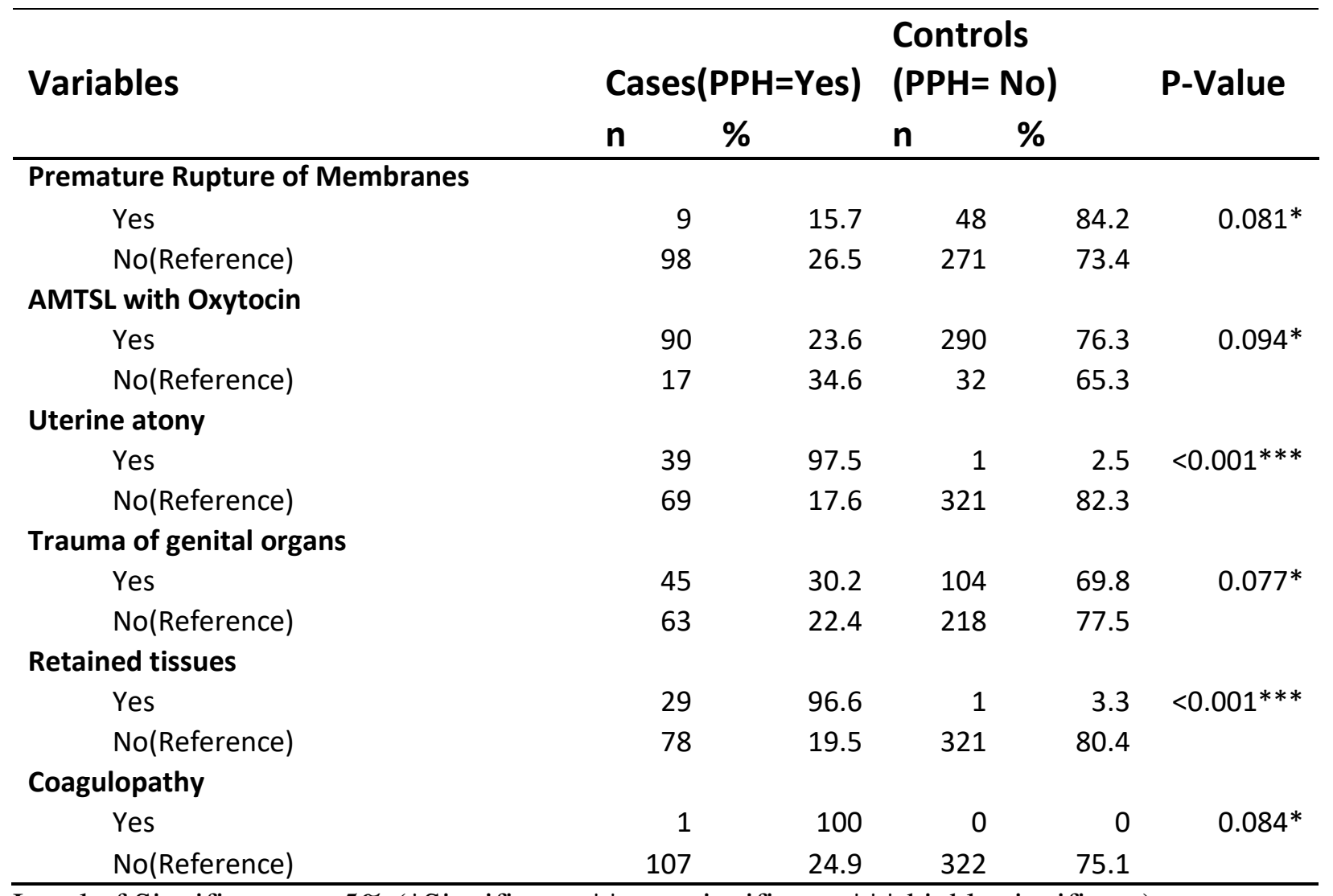

Level of Significance at 5\% (*Significant; **very significant; *** highly significant)

The risk factors found to be associated with primary PPH at bivariate analysis were further analyzed to control for possible confounders. This multivariate analysis indicated that the antepartum risk factors were: $\mathrm{Hb}$ level of $<11 \mathrm{gr} / \mathrm{dL}$ on admission to labour, multiple pregnancy, intrauterine foetal death, antepartum haemorrhage and PROM (Table 3). The risk of developing primary PPH is almost two times higher among childbearing women with intrauterine foetal death (95\% CI 0.93- 4.03, $P=0.077$ ); with multiple pregnancy (95\% CI 1.11- 3.01, $P=0.016$ ); with haemoglobin $<11 \mathrm{gr} / \mathrm{dL}$ on admission to labour (anaemic women) (95\% CI 1.00- 2.30, $P=0.05$ ) ; the risk is three times more in women with APH $(95 \%$ CI 1.80- 6.26, $P<0.001)$ than in women without these risk factors. Primary PPH was slightly more prevalent in women experiencing PROM than among those without this condition. $(95 \%$ CI $0.32-1.05, P=0.077)$ than in women without.

During the intrapartum and immediate postpartum periods, the risk of developing primary PPH is almost seven times greater in childbearing women who experience uterine atony than in births not 
complicated with uterine atony $(95 \%$ CI 4.78- 9.38, $P<0.001)$. The risk of PPH was four times higher in women with retained tissues than in those without $(95 \% \mathrm{CI} 2.87-6.51, P<0.001)$. The risk is twice more in women with genital organ lacerations than in women without this complication (95\% CI 1.49-3.097, $P<0.001)$. The problem of coagulopathy was not significantly correlated with primary PPH.

Table 3. Risk ratios, 95\% Confidence Interval (CI) of childbearing Women with primary Postpartum Haemorrhage

\begin{tabular}{lccc}
\hline \multicolumn{1}{c}{ PPH risk factors } & Risk ratio & $\begin{array}{c}\text { 95\% Confidence } \\
\text { Interval }\end{array}$ & P-Value \\
\hline Haemoglobin $<11 \mathrm{gr} / \mathrm{dL}$ & 1.519 & {$[1.000-2.309]$} & $0.050^{* *}$ \\
Multiple pregnancy & 1.838 & {$[1.119-3.017]$} & $0.016^{* *}$ \\
Intrauterine fetal death & 1.937 & {$[0.931-4.030]$} & $0.077^{*}$ \\
Antepartum haemorrhage & 3.362 & {$[1.805-6.261]$} & $<0.001^{* * *}$ \\
& & & \\
Premature Rupture of & 0.585 & {$[0.323-1.058]$} & $0.077^{*}$ \\
Membranes & & & $<0.001 * * *$ \\
Uterine atony & 6.701 & {$[4.784-9.384]$} & $<0.001 * * *$ \\
Retained tissues & 4.326 & {$[2.871-6.518]$} & $<0.001 * * *$ \\
Genital trauma & 2.149 & {$[1.491-3.097]$} & \\
\hline
\end{tabular}

Level of Significance at $5 \%(*$ Significant; $* *$ very significant; $* * *$ highly significant $)$

\section{Discussion}

PPH often occurs in the absence of known risk factors. In the present study, we investigated and modelled the potential risk factors of primary PPH among women admitted to postpartum units of five selected health facilities of the Northern Province of Rwanda.

The prevalence of PPH in our study participants was $25.1 \%$, which indicates that PPH was common in our study population as confirmed by other studies [56, 57]. This result was likely due to the fact that majority of women included in this study gave birth in district hospital settings 
(76.2\%) that receive referrals from health centres of the catchment area. The prevalence of PPH is also noted to be high in Yemen (29.1\%) [64]. This variation in prevalence of PPH might be due to difference in study design, social stability, cultural difference and maternal health care services accessibility.

As highlighted by Main et al., [65], the risk assessment for PPH should be undertaken during antepartum care, at admission to labour and delivery, during labour and delivery and postpartum, as $\mathrm{PPH}$ risk factors can change or evolve throughout the perinatal period. Our assessment demonstrated that factors associated with primary PPH are found throughout the course of childbearing period; the antepartum, intrapartum and early postpartum periods including causes of PPH for the continuity of care in early detection and prevention of PPH.

\section{Antepartum risk factors}

Antepartum haemorrhage, multiple pregnancy, intrauterine foetal death, $\mathrm{Hb}$ level on admission to labour and PROM demonstrated an increased RR for developing PPH which was higher in women with these risks factors than in women without.

Antepartum haemorrhage (APH) was the strongest predictor among study participants and was associated with triple the risk for developing primary PPH. This finding concurs with the guideline released by the Royal College of Obsetricians and Gynecologists [66]in the UK, which states that PPH should be anticipated in women who have experienced APH [66]. A study in Brazil demonstrated that severe maternal outcome due to antepartum and intrapartum haemorrhage was highly prevalent [72]. APH might be associated with placental abruption or placenta praevia, placental anomalies and local genital tract disorders, such as cervicitis and neoplasms. No definitive cause is diagnosed in some patients [67]. In our study, insufficient data were available to classify APH, and participants were not sure about the kind of APH they experienced. A comprehensive documentation of client obstetrical history and antepartum complications could give light to birth preparedness and early detection of PPH.

Multiple pregnancy was one of the strongest predictors of primary PPH in this study, which is similar to previous studies[9, 18, 30,68]. The over distension induced by multiple pregnancy increases the risk of uterine atony with overstretching of uterine muscle. In addition, the large placental size in multiple pregnancy increases the insertion surface area which bleeds after 
childbirth. Multiple pregnancy contributes to an increased fundal height which is shown to be a predictor for PPH [22]. This finding calls for more vigilance on the part of practitioners attending labour and births to identify women at risk, to have adequate preparation and plan for early intervention to prevent PPH. The WHO encourages further research to determine the role of symphysis-fundal height measurement in detecting abnormal foetal growth and other risk factors for perinatal morbidity (multiple pregnancy, polyhydramnios, macrosomia) in settings where antenatal ultrasound is not available [69].

Intrauterine foetal death (IUFD) - also called stillbirth - was prevalent in participants of our study who experienced primary PPH, again supporting the existing evidence. PPH was observed in 10\% of IUFD cases in a US study [70] and in $12 \%$ of patients in a study on aetiology and maternal complications of IUFD [75]. In case of stillbirth, PPH might be associated with retained placenta which was noted in a very high number of women $(23 \%)$ in a retrospective chart review to evaluate stillbirth demographics, pregnancy and maternal risk factors, and complications of labour and birth [74].

Our study was conducted during the Covid-19 outbreak (study period: January -June 2020). Clinicians and caregivers need to be extra vigilant for maternal complications in pregnant women with Covid-19 [76]. In response to the Covid-19 outbreak, Rwanda put in place measures to contain the disease and online services were encouraged [71]. It is not clear how pregnant women experienced regular antenatal care during the pandemic. Creating an individual care plan for highrisk pregnancies instead of a virtual approach may improve outcomes in this type of situation [78]. Since pregnant women are potentially at risk of obstetric complications including PPH, regular consultation with a health professional is recommended throughout the course of pregnancy, because it is an optimal opportunity for healthcare providers to identify women who are at increased risk early on during pregnancy and to deliver necessary support and educate pregnant women on unexpected events [72].

Low $\mathrm{Hb}$ level $(<11 \mathrm{gr} / \mathrm{dL})$ on admission to labour is worth noting because it is an indication of anaemic pregnant women so that health care providers can be proactive in prevention of PPH. For participants included in this study the risk of PPH was 1.5 times higher for anaemic women than for non-anaemic women. Again, our findings are consistent with earlier research [27]. The key findings from Rwanda Demographic Health Survey 2019-20 demonstrated that among pregnant 
women, those in the lowest wealth quintile are more likely to be anaemic $(\mathrm{Hb}<11 \mathrm{gr} / \mathrm{dL})$ than other women [2]. Our multivariate analysis also demonstrated PROM to be prevalent in women who developed primary PPH which was identified as potential risk factor in earlier case control study[9]. PROM is complicated with chorioamnionitis which was found to be associated with an increased risk of severe atonic PPH in previous studies[31, 73].

In addition to prevalent risk factors, our analysis demonstrated significant association of some other risk factors with primary PPH with a $P$-value $<0.05$. These included maternal age (being >35 was associated with higher risk), type of health facility where birth take place, BMI, holding medical insurance, grandmultiparity, previous $\mathrm{PPH}$, anaemia during pregnancy and active management of third stage of labour. The significant antepartum risk factors for primary PPH observed in our study echoed previous evidence $[18,22]$. In contrast to previous studies $[9,18,19$, 22], where these factors were found to be predictors of PPH, our multivariate analysis did not find these variables to be associated with increased risk of primary PPH. This dissimilarity might be associated with difference in sample size and in data collection period. A large scale case control study would investigate further all potential risk factors for improved PPH prevention.

\section{Intrapartum risk factors and causes of PPH}

For intrapartum and immediate postpartum factors analyzed in this study, with the exception of coagulopathy, the other causes of PPH demonstrated a strong association with primary PPH (uterine atony, trauma of genital organs and retained tissues). In this study, uterine atony was found to be the most prevalent cause of primary $\mathrm{PPH}$, followed by retained tissues and genital trauma. Our findings concur with previous studies highlighting that the main cause of primary PPH and the primary direct cause of maternal morbidity globally was uterine atony $[5,6,17]$. However, one other study concluded that genital tract laceration was the commonest cause of primary $\mathrm{PPH}$ followed by uterine atony [13]. The active management of the third stage of labour with uterotonics was found to reduce the risk of PPH especially due to atonic uterus, and injectable oxytocin is the treatment recommended by WHO [36].

Our study demonstrated that $88.6 \%$ women who gave birth at the five health facilities in the Northern Province of Rwanda received an intramuscular uterotonic to manage the third stage of labour and hence to prevent PPH due to uterine atony. This rate is low compared to a prospective cohort study conducted in Uganda to understand the relative contributions of different risk factors 
for PPH. The results revealed that almost all (97\%) women delivering at the health facilities health in rural Uganda received uterotonics. This difference might be associated with inadequate management of the third stage of labour as revealed by previous studies $[4,42,74]$ in relation to factors affecting the prevention of $\mathrm{PPH}$. This is also confirmed by findings from an endline evaluation of the 50,000 Happy Birthdays Project implemented in Rwanda between 2018-2020. The programme involved training midwives, nurses and other health workers to apply the Helping Mothers Survive (HMS) and Helping Babies Survive (HBS) techniques to address the leading causes of maternal and neonatal mortality including PPH. The baseline assessment demonstrated that $87.2 \%$ of women giving birth received uterotonics immediately after birth while after training, the endline evaluation revealed that $99.9 \%$ of women giving birth had received uterotonics for PPH prevention [75].

\section{Strengths and limitations}

The main strength of the present case-control study was the quality of the data source. The review of medical records combined with structured interviews with participants during the hospital stay allowed to collect accurate data and minimized missing data. Case control studies are useful to study multiple exposures in the same outcome [40]. Hence we were able to evaluate potential risk factors for primary PPH using a broad selection of demographic and clinical variables which may not be easily retrieved from registries and from other medical records. In addition, reading the medical records allowed us to record accurate information on the causes of PPH. Assessing risk factors in retrospect is a limitation in this study. In order to minimize selection bias, we selected all possible cases of primary PPH and a random sample of controls from the same source population. Blood loss was estimated visually by health care providers in the five health facilities included in our study, and the blood loss may have been under or overestimated, this might have led also to missing some PPH cases. To minimize this risk, we trained research assistants to identify cases of PPH based on clinical features and visual estimation of blood loss as recommended by Hancock et al., [39] that the diagnosis and early detection of PPH may rely on factors other than volume. 


\title{
Conclusions
}

Primary PPH is a common occurrence in the Northern Province of Rwanda. Antepartum haemorrhage, intrauterine foetal death, multiple pregnancy and $\mathrm{Hb}$ Level $<11 \mathrm{gr} / \mathrm{dL}$ on admission to labour and PROM were prevalent antepartum risk factors in primary PPH. During the intrapartum and immediate postpartum period, the main prevalent causes of PPH were uterine atony, retained tissues; and genital organ lacerations identified after birth. Since primary PPH is relatively common, all obstetric unit members should be prepared to manage mothers who experience it. Progress towards improvement of maternal health will require dedicated efforts to improve risk assessment, to encourage proper documentation of maternal information during the course of childbirth for an early detection of women at risk and prevention of PPH in Rwanda. Improving the quality of proactive prevention should be a priority for policy makers, health managers and service providers to reduce the high risks of maternal mortality and morbidity associated with PPH. Large scale studies are needed to investigate further potential PPH risk factors.

\begin{abstract}
Abbreviations
PPH: Postpartum haemorrhage; RATP: Risk assessment tool for the prediction and prevention of PPH; APH: Antepartum haemorrhage; CI: Confidence Interval; RR: Risk Ratio; IUFD: Intrauterine faeto-dealth; Hb: Haemoglobin; AMSTL: Active Management of Third Stage of Labour; PROM: Premature Rupture of Membranes.
\end{abstract}

\section{Declarations}

\section{Acknowledgements}

We acknowledge the University of Rwanda and Western University through Training Support Access Model Project for supporting this research. We would like to thank the administration of Byumba, Nemba, Ruli, Rutongo district hospitals and the in charge of Rutare medicalized health centre for granting us permission to conduct this study. We also acknowledge the research assistants for their support in data collection. Our sincere gratitude goes to Dr. Andrea Nove, technical director at Novametrics in UK for her professional guidance and English editing of the present paper.

\section{Authors' contributions}

$\mathrm{OB}, \mathrm{MN}, \mathrm{AU}, \mathrm{ME}$ designed research protocol. $\mathrm{OB}, \mathrm{MN}$ contributed to data collection, $\mathrm{OB}$, IK conducted data analysis and participated in drafting and editing the manuscript. All authors reviewed, edited, contributed and approved the final version of the manuscript. 


\section{Funding}

Research for the Training, Support and Access Model for Maternal, Newborn and Child Health in Rwanda Project has been undertaken with financial support to the University of Western Ontario from the Government of Canada provided through Global Affairs Canada. The research team acted independently from the funders who had no role in the data collection, analysis, interpretation of data, writing of the report, or in the decision to submit the article for publication.

\section{Availability of data and materials}

The datasets used and analysed during the current study are available from the corresponding author on reasonable request.

\section{Ethics approval and consent to participate}

All procedures performed in this study involving human participants were approved by Institution Review Board at the College of Medicine and Health Sciences, University of Rwanda (ethical approval No 439/CMHS IRB/2019) prior to enrolment of participants. Permissions to conduct the study was also obtained from all the health facilities included in this study. The study was conducted in compliance with the Declaration of Helsinki. Informed written consent was obtained from all participants. Moreover, the principle of Justice, Beneficence, and Non-Maleficence was maintained and followed throughout the conduct of this study.

\section{Consent for publication}

Not applicable.

\section{Competing interests}

The authors declare that they have no competing interests.

\section{Author details}

${ }^{1}$ College of Medicine and Health Sciences, University of Rwanda, 3286, Kigali, Rwanda; ${ }^{2}$ University of the Western Cape, Robert Sobukwe Rd, Bellville, Cape Town, 7535, South Africa; ${ }^{3}$ University of Western Ontario, Arthur Labatt Family School of Nursing,1151 Richmond St, London, ON N6A 3K7, Canada. 


\section{References}

1. World Health Organization. Maternal mortality. Geneva, Switzerland: World Health Organization, 2019.

2. National Institute of Statistics of Rwanda (NISR) [Rwanda], Ministry of Health (MOH) [Rwanda], ICF International. Rwanda Demographic and Health Survey 2019-20 Key Indicators Report. Kigali ,Rwanda Rockville,Maryland, USA: NISR and ICF, 2020.

3. United Nations. Transforming our World: The 2030 Agenda for Sustainable Development. A/RES/70/1. 2016 A/RES/70/1.

4. Bazirete O, Nzayirambaho M, Uwimana MC, Umubyeyi A, Marilyn E. Factors affecting the prevention of postpartum hemorrhage in Low- and Middle-Income Countries: A scoping review of the literature. Journal of Nursing Education and Practice. 2020;11(1):66.

5. World Health Organization. WHO recommendations for the prevention and treatment of postpartum haemorrhage. World Health Organization, 20 Avenue Appia, 1211 Geneva 27, Switzerland: 2012.

6. Ngwenya S. Postpartum hemorrhage: incidence, risk factors, and outcomes in a low-resource setting. Int J Womens Health. 2016;8:647-50.

7. Sheldon WR, Blum J, Vogel JP, Souza JP, Gulmezoglu AM, Winikoff B, et al. Postpartum haemorrhage management, risks, and maternal outcomes: findings from the World Health Organization Multicountry Survey on Maternal and Newborn Health. BJOG : an international journal of obstetrics and gynaecology. 2014;121 Suppl 1:5-13.

8. Sayinzoga F, Bijlmakers L, van Dillen J, Mivumbi V, Ngabo F, van der Velden K. Maternal death audit in Rwanda 2009-2013: a nationwide facility-based retrospective cohort study. BMJ Open. 2016;6(1):e009734.

9. Nyflot LT, Sandven I, Stray-Pedersen B, Pettersen S, Al-Zirqi I, Rosenberg M, et al. Risk factors for severe postpartum hemorrhage: a case-control study. BMC pregnancy and childbirth. 2017;17(1):17.

10. Nyfløt LT, Stray-Pedersen B, Forsén L, Vangen S. Duration of labor and the risk of severe postpartum hemorrhage: A case-control study. PloS one. 2017;12 (4):1-10.

11. Weeks A. The prevention and treatment of postpartum haemorrhage: what do we know, and where do we go to next? BJOG : an international journal of obstetrics and gynaecology. 2015;122:202-12.

12. Rocha Filho EA, Costa ML, Cecatti JG, Parpinelli MA, Haddad SM, Pacagnella RC, et al. Severe maternal morbidity and near miss due to postpartum hemorrhage in a national multicenter surveillance study. International journal of gynaecology and obstetrics: the official organ of the International Federation of Gynaecology and Obstetrics. 2015;128(2):131-6.

13. Ifeadike CO, Uchenna Eleje G, Stanley Umeh U, Okaforcha EI. Emerging trend in the etiology of postpartum hemorrhage in a low resource setting. Journal of Pregnancy and Neonatal Medicine. 2018;02(02):34-40.

14. Abera K. Magnitude, Associated Factors and Maternal Outcome of Postpartum Hemorrhage at Black Lion Specialised Hospital From Jan. 1, 2009 To Dec. 30, 2013 GC 14632 Thesis in Library: Addis Ababa University; 2014.

15. Edwards HM. Aetiology and treatment of severe postpartum haemorrhage. University of Copenhagen: University of Copenhagen; 2017.

16. James AH, McLintock C, Lockhart E. Postpartum hemorrhage: when uterotonics and sutures fail. Am J Hematol. 2012;87 Suppl 1:S16-22.

17. Halle-Ekane G, Emade F, Bechem N, Palle J, Fongaing D, Essome H, et al. Prevalence and Risk Factors of Primary Postpartum Hemorrhage after Vaginal Deliveries in the Bonassama District Hospital, Cameroon. International Journal of Tropical Disease \& Health. 2016;13(2):1-12.

18. Ononge S, Mirembe F, Wandabwa J, Campbell OM. Incidence and risk factors for postpartum hemorrhage in Uganda. Reproductive health. 2016;13:38.

19. Kebede BA, Abdo RA, Anshebo AA, Gebremariam BM. Prevalence and predictors of primary postpartum hemorrhage: An implication for designing effective intervention at selected hospitals, Southern Ethiopia. PloS one. 2019; 14(10):e0224579.

20. Gani N, Ali T. Prevalence and factors associated with maternal postpartum haemorrhage in Khyber Agency, Pakistan. Journal of Ayub Medical College,. 2013;25(1-2):81-5. 
21. Sittiparn W, Siwadune T. Risk Score for Prediction of Postpartum Hemorrhages in Normal Labor at Chonburi Hospital. Journal of the Medical Association of Thailand. 2017;100(4):382-8.

22. Natakorn I-T, Ratanasiri A, Nutravong T, Boonprasert K, Pikul TN. Risk Scoring System for the Prediction of Postpartum Blood Loss over $300 \mathrm{~mL}$ at Chiang Rai Regional Hospital. Siriraj Medical Journal. 2019;71(1):110-6.

23. Temesgen MA. Magnitude of Postpartum Hemorrhage among Women Delivered at Dessie Referral Hospital, South Woll, Amhara Region, Ethiopia. Journal of Womens Health Care. 2017;06(04).

24. Traoré Y, Téguété I, Bocoum A, Traoré M, Dao S, Bomini MK, et al. Management and Prognosis of Early Postpartum Hemorrhage in African Low Setting Health. Open Journal of Obstetrics and Gynecology. 2018;08(01):1-9.

25. Tort J, Rozenberg P, Traore M, Fournier P, Dumont A. Factors associated with postpartum hemorrhage maternal death in referral hospitals in Senegal and Mali: a cross-sectional epidemiological survey. BMC pregnancy and childbirth. 2015;15:235.

26. Nakagawa K, Yamada T, Cho K, Akaishi R, Kohgo Y, Hanatani K, et al. Independent Risk Factors for Postpartum Haemorrhage. Critical Care Obstetrics and Gynecology. 2016;2(2:10):1-7.

27. Frass KA. Postpartum hemorrhage is related to the hemoglobin levels at labor: Observational study. Alexandria Journal of Medicine. 2019;51(4):333-7.

28. Abdul-Kadir R, McLintock C, Ducloy AS, El-Refaey H, England A, Federici AB, et al. Evaluation and management of postpartum hemorrhage: consensus from an international expert panel. Transfusion. 2014;54(7):1756-68.

29. Huang Y, Bao Y, Qu X, Yuan L, Ying H. Factors associated with different levels of postpartum hemorrhage in patients experiencing blood transfusion during cesarean section. Int J Clin Exp Med. 2016;9(8):1667581.

30. Kramer MS, Dahhou M, Vallerand D, Liston R, Joseph KS. Risk Factors for Postpartum Hemorrhage: Can We Explain the Recent Temporal Increase? Journal of Obstetrics and Gynaecology Canada. 2011;33(8):810-9.

31. Goueslard K, Revert M, Iacobelli S, Cottenet J, Roussot A, Combier E, et al. Incidence and Risk Factors of Severe Post-Partum Haemorrhage: A Nationwide Population-Based Study from a Hospital Database. Quality in Primary Care. 2017;25 (2):55-62.

32. Briley A, Seed PT, Tydeman G, Ballard H, Waterstone M, Sandall J, et al. Reporting errors, incidence and risk factors for postpartum haemorrhage and progression to severe PPH: a prospective observational study. BJOG : an international journal of obstetrics and gynaecology. 2014;121(7):876-88.

33. Dunning T, Harris JM, Sandall J. Women and their birth partners' experiences following a primary postpartum haemorrhage: a qualitative study. BMC pregnancy and childbirth. 2016;16:80.

34. Mousa HA, Blum J, Abou El Senoun G, Shakur H, Alfirevic Z. Treatment for primary postpartum haemorrhage. The Cochrane database of systematic reviews. 2014(2):CD003249.

35. Milman N. Postpartum anemia I: definition, prevalence, causes, and consequences. Ann Hematol. 2011;90(11):1247-53.

36. Vogel JP, Williams M, Gallos I, Althabe F, Oladapo OT. WHO recommendations on uterotonics for postpartum haemorrhage prevention: what works, and which one? BMJ global health. 2019;4(2):e001466.

37. Atukunda EC, Mugyenyi GR, Obua C, Atuhumuza EB, Musinguzi N, Tornes YF, et al. Measuring PostPartum Haemorrhage in Low-Resource Settings: The Diagnostic Validity of Weighed Blood Loss versus Quantitative Changes in Hemoglobin. PloS one. 2016;11(4):e0152408.

38. Diaz V, Abalos E, Carroli G. Methods for blood loss estimation after vaginal birth. Cochrane Database of Systematic Reviews. 2014.

39. Hancock A, Weeks AD, Lavender DT. Is accurate and reliable blood loss estimation the 'crucial step' in early detection of postpartum haemorrhage: an integrative review of the literature. BMC pregnancy and childbirth. 2015;15:230.

40. Singh Setia M. Methodology Series Module 2: Case-control Studies. Indian Journal of Dermatology. 2016;61(2):146-51.

41. Song JW, Chung KC. Observational studies: cohort and case-control studies. Plast Reconstr Surg. 2010;126(6):2234-42. 
42. Bazirete O, Nzayirambaho M, Umubyeyi A, Uwimana MC, Evans M. Influencing factors for prevention of postpartum hemorrhage and early detection of childbearing women at risk in Northern Province of Rwanda: beneficiary and health worker perspectives. BMC pregnancy and childbirth. 2020;20(1):678.

43. Bazirete O, Nzayirambaho M, Umubyeyi A, Uwimana MC, Marilyn E. Who is at risk? The development of a tool to predict and prevent postpartum hemorrhage. Journal of Nursing Education and Practice. 2020;11(4):62.

44. Rwanda Ministry of Health. Service Packages for Upgraded Health Centers,Rwanda Healthcare System. Kigali Rwanda: Ministry of Health, 2019.

45. National Institute of Statistics of Rwanda (NISR) [Rwanda], Ministry of Health (MOH) [Rwanda], ICF International. Rwanda Demographic and Health Survey 2014-15. Rockville, Maryland, USA: 2016.

46. Rwanda Ministry of Health. Kwita ku mugore utwite, uwabyaye n'uruhinja mu rugo. 2015.

47. Rwanda Ministry of Health. Formation Continue en Soins Obstétricaux et Néonatals d'Urgence de Base. In: Maternal New Born Child and Community Health Division, editor. Kigali, Rwanda2016. p. 1-145.

48. Jabbar S, Perveen S, Kumar R. Secondary postpartum haemorrhage: causes and management in a tertiary care hospital. Annals ASH KMDC. 2019;24(1):38-44.

49. YENIPINAR A, KOÇ Ş, ÇANGA D, KAYA F. Determining Sample Size in Logistic regression with GPower. Black Sea Journal of Engineering and Science. 2019;2(1):16-22.

50. StataCorp LLC. Stata Statistical Software: Release 15 College Station, TX, 2017: College Station, TX; 2017 [cited 2021 January 27]. Available from: www. stata. com/features/documentation/.

51. United Nations. World Population Ageing 2019-Highlights. New York: Department of Economic and Social Affairs, Population Division, 2019 ST/ESA/SER.A/430.

52. Weir CB, Jan A. BMI Classification Percentile And Cut Off Points. 2019.

53. Strutz KL, Richardson LJ, Hussey JM. Preconception health trajectories and birth weight in a national prospective cohort. J Adolesc Health. 2012;51(6):629-36.

54. Keller SP, Kelvin EA. Munro's Statistical Methods for Health Care Research: Lippincott Williams \& Wilkins; 2013.

55. Zou G. A Modified Poisson Regression Approach to Prospective Studies with Binary Data. American Journal of Epidemiology. 2004;159(7):702-6.

56. McNutt LA, Wu C, Xue X, Hafner JP. Estimating the relative risk in cohort studies and clinical trials of common outcomes. Am J Epidemiol. 2003;157(10):940-3.

57. Lindquist K. How can I estimate relative risk using GLM for common outcomes in Cohort studies? University of California, Los Angeles: UCLA: Statistical Consulting Group; 2020 [cited 202024 November ]. Available from: https://stats.idre.ucla.edu/stata/faq/how-can-i-estimate-relative-risk-using-glm-forcommon-outcomes-in-cohort-studies/.

58. Marschner IC. Relative Risk Regression for Binary Outcomes: Methods and Recommendations. Australian \& New Zealand Journal of Statistics. 2015;57(4):437-62.

59. Petersen MR, Deddens JA. A comparison of two methods for estimating prevalence ratios. BMC Med Res Methodol. 2008;8:9.

60. Kellar SP, Kelvin EA. Munro's STATISTICAL METHODS FOR HEALTH CARE RESEARCH. 6th ed. United States of America: Wolters Kluwer HealthI Lippincott Williams \& Wilkins; 2013.

61. Sedgwick P. Case-control studies: measures of risk. BMJ. 2013;346:f1185.

62. Greenland S. Model-based Estimation of Relative Risks and Other Epidemiologic Measures in Studies of Common Outcomes and in Case control Studies. American Journal of Epidemiology. 2004;160:301-5.

63. Carter RE, Lipsitz SR, Tilley BC. Quasi-likelihood estimation for relative risk regression models. Biostatistics. 2005;6(1):39-44.

64. Kaima A. Frass. Postpartum hemorrhage is related to the hemoglobin levels at labor: Observational study. Alexandria Journal of Medicine. 2015;51(4):333-7.

65. Main EK, Goffman D, Scavone BM, Low LK, Bingham D, Fontaine PL, et al. National Partnership for Maternal Safety: Consensus Bundle on Obstetric Hemorrhage. Journal of obstetric, gynecologic, and neonatal nursing : JOGNN. 2015;44(4):462-70.

66. Royal College of Obsetricians and Gynecologists. Antepartum Haemorrhage. 2011.

67. Yeung SW, Tam WH, Cheung RY. The risk of preterm delivery prior to 34 weeks in women presenting with antepartum haemorrhage of unknown origin. Aust N Z J Obstet Gynaecol. 2012;52(2):167-72. 
68. Lutomski JE, Byrne BM, Devane D, RA. G. Increasing trends in atonic postpartum haemorrhage in Ireland: an 11-year population-based cohort study. BJOGAn International Journal of Obstetrics and Gynaecology. 2012;119(9):306-14.

69. Organization WH. WHO recommendation on symphysis-fundal height measurementGeneva: WHO Reproductive Health Library, 2016.

70. Gold KJ, Mozurkewich EL, Puder KS, Treadwell MC. Maternal complications associated with stillbirth delivery: A cross-sectional analysis. J Obstet Gynaecol. 2016;36(2):208-12.

71. World Health Organization. COVID-19 in Rwanda: A country's response. Geneva: World Health Organization, 2020.

72. Kolola T, Morka W, Abdissa B. Antenatal care booking within the first trimester of pregnancy and its associated factors among pregnant women residing in an urban area: a cross-sectional study in Debre Berhan town, Ethiopia. BMJ Open. 2020;10(e032960):1-6.

73. Rodrigo Rexy Rodrigo M, Kannamani A. Perinatal and Maternal Outcome in Premature Rupture of Membranes. Journal of Evolution of Medical and Dental Sciences. 2016;5(51):3245-7.

74. Tenaw Z, Yohannes Z, Amano A. Obstetric care providers' knowledge, practice and associated factors towards active management of third stage of labor in Sidama Zone, South Ethiopia. BMC pregnancy and childbirth. 2017;17(1):292.

75. Rwanda Association of Midwives, International Confederation of Midwives, Novametrics. 50,000 Happy Birthdays Project ,Endline evaluation, April 2020: Summary of results in Rwanda. Kigali, Rwanda: Novametrics, 2020. 
Figures

\section{SOURCE POPULATION}

All women giving birth in the 5 selected health facilities of the Northern Province of

Rwanda

January, $1^{\text {st }} 2020$ - June $30^{\text {th }} 2020$

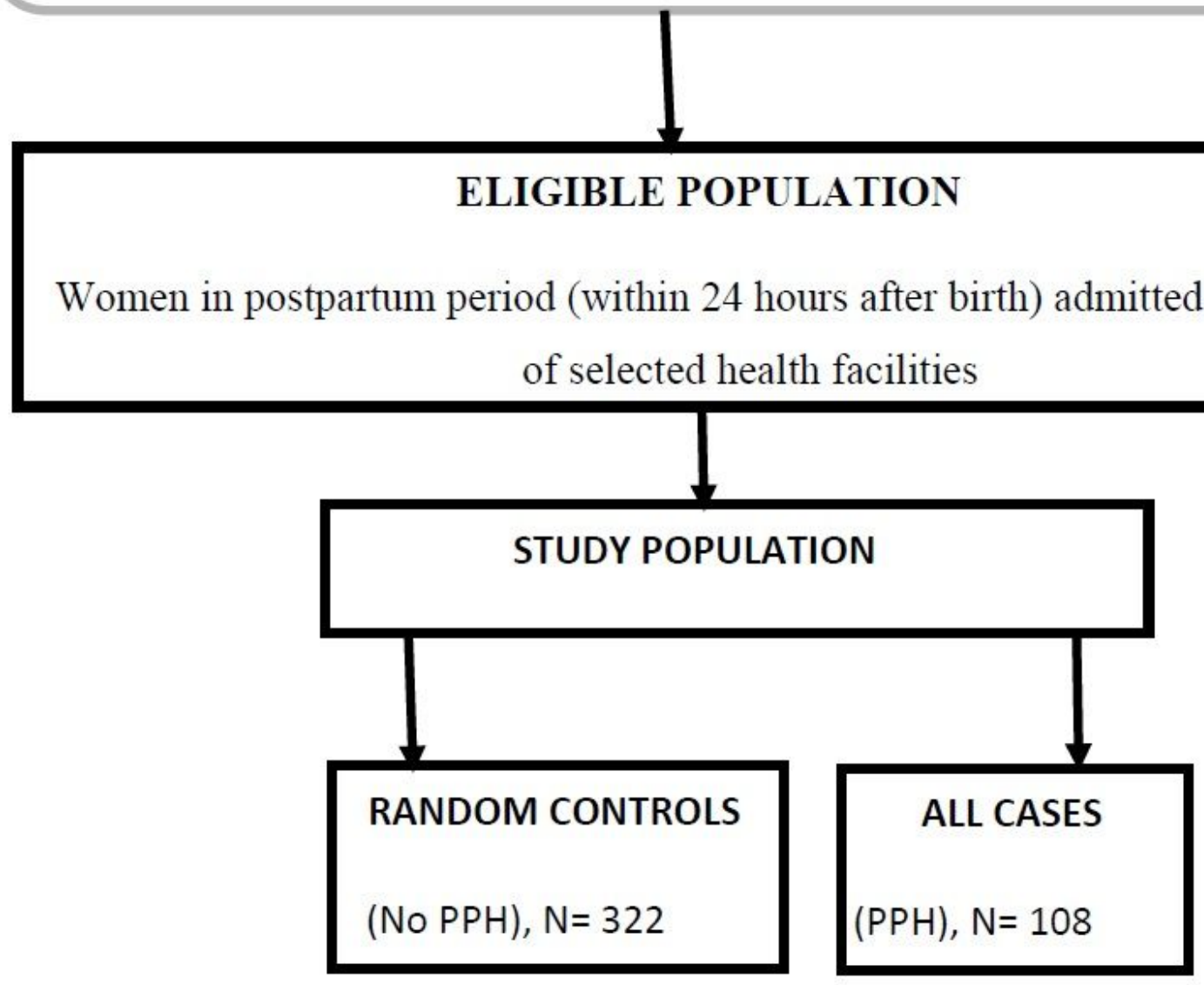

Figure 1

Selection of study subjects. PPH: Postpartum haemorrhage

\section{Supplementary Files}

This is a list of supplementary files associated with this preprint. Click to download.

- 16022021STROBEchecklistcasecontrol.pdf 